\title{
CYTOPLASMIC INCLUSIONS IN MALE GERM CELLS OF THE FOWL TICK, ARGAS MINIATUS, AND HISTOGENESIS OF THE SPERMATOZOON ${ }^{1}$
}

\author{
D. B. CASTEEL
}

ONE TEXT Figure AND EIght PLATES

CONTENTS

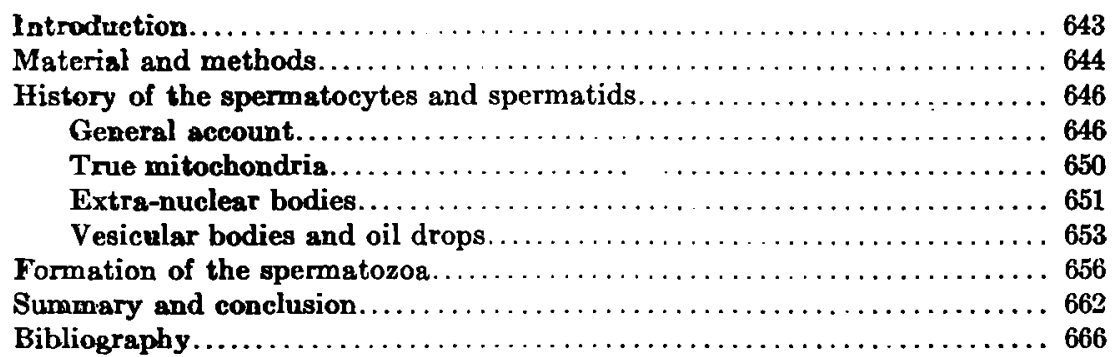

\section{INTRODUCTION}

This paper is more particularly concerned with the cytoplasmic elements found in the male germ cells of the chicken tick, Argas miniatus, with special reference to the occurrence and behavior of the mitochondria throughout the complete history of spermatogenesis, from spermatogonia to mature spermatozoa. As will be noted, the nuclear components of the cell are considered only in so far as they bear relations to extra-nuclear substances.

In view of the fact that the spermatozoa of many Acarines are of relatively large size and of markedly atypical form it is surprising to find that the literature dealing with them is but slight in amount. The more important studies upon the histogenesis of tick spermatozoa are those of Christophers ('06), Norden-

- Contribution from the Zoological Laboratory of the University of Texas, No. 129. 
skilöld ('07), Bonnet ('07) and Samson ('09) as indicated in the latter portion of this paper. All of these investigators are concerned more particularly with the metamorphosis of the spermatozoon from the spermatid, and they give but brief and incomplete accounts of the preceding stages.

My attention was attracted to the growing spermatocytes and the spermatids of Argas by their relatively large size and the prominence of their cytoplasmic inclusions. This account represents the results of a work undertaken in the hope that a thorough study of these bodies throughout the history of the male germ cells might add to our knowledge of those problematical structures, the mitochondria, and that our data upon the spermiohistiogenesis of the Acarines might be enlarged. For the sake of conciseness and to avoid needless repetition in the literature, reference is limited to papers which bear very directly upon the subject and no general review or discussion of cytoplasmic inclusions is attempted. Comprehensive reviews may be found in the works of Benda (1899, '03), Meves ('08, '10 et al.), Fauré-Fremiet ('10), Duesberg ('11), Hegner ('14), Cowdry ('12, '16) and others.

During the progress of my work the germ cells of several species of ticks have been examined for comparison. I am indebted to Mr. F. C. Bishopp of the United States Department of Agriculture for material of this nature sent to me from the Dallas Laboratory. I also wish to express my appreciation of the facilities afforded me during the summer of 1915 by Prof. F. R. Lillie at the Marine Biological Laboratory at Woods Hole. I am particularly indebted to Dr. E. V. Cowdry for certain vital stains and for helpful suggestions regarding technique and interpretation.

\section{MATERIAL AND METHODS}

The chicken-tick, fowl-tick or blue-bug, Argas miniatus (Koch), is a common parasite of fowls in the southwestern portion of the United States. It is synonymous with Argas persicus which is found in many parts of the world, in tropical and subtropical regions. The adult ticks are readily obtained from an infested 
roost where they are often found in enormous numbers. During the day the adults and nymphs conceal themselves in cracks and crevices between the boards of the hen-house and from these hiding places they issue at night to prey upon the fowls. Only the seed ticks or newly hatched nymphs feed continuously upon the fowls, and this period lasts from but three to ten days. The life-history, habits and distribution of Argas are well described by Bishopp ('13).

All but the final stages in the development of the male germ cells of Argas may be obtained from the testes and sexual ducts of the male. The testes are two long tubes which lie loosely coiled within the body. Longitudinal sections through the testes reveal the germ cells in successive stages of development from the early spermatogonia onward, and such sections make possible the study of many stages from the same slide where they have all been subjected to the same fixing and staining technique. The final stages in development occur within the spermatophore sacs in the genital ducts of female and as the spermatozoa leave the spermatophores.

Both sections and smear preparations were employed and numerous observations were made upon the living cells both with and without vital dyes. Many fixing solutions were used, the most satisfactory being Flemming's stronger solution, and the fluids of Altmann, Benda, Meves and Bensley. Osmic acid (in 2 per cent solution and in the form of vapor) also gave good results. Bichromate-formalin was less satisfactory. The mixtures of Carnoy, Gilson and Bouin were used for purposes of comparison. Bensley's acid fuchsin with counter stain of methyl green, methyl blue, or toluidin blue gave the best differential results for mitochondria although the alizarin-crystal-violet method of Benda (or Duesberg's modification) is equally satisfactory in certain stages of development. Haidenhain's ironhaematoxylin was employed after all fixatives for comparison. As vital stains for mitochondria janus green (Hoechst) and its derivative diethylsafranin are most satisfactory. Certain special dyes, brilliant cresyl blue B extra, Sudan III, and others were found valuable for analysis. Prolonged study of the living 
germ cells is rendered difficult by the rapidity with which they disintegrate after removal from the body of the tick. Even in the most suitable medium, a modification of Lock's solution, they remain normal for but a short time.

\section{HISTORY OF THE SPERMATOCYTES AND SPERAIATIDS}

\section{General account}

As a basis for a review of the developmental processes which occur during the history of the germ cells of the tick it will be well to consider first the composition of a spermatocyte which is approaching the end of the growth period (fig. 9). The cell exhibits a distinct outer layer (s.l.) well demarcated from the underlying cytoplasm, composed of numerous excessively fine striae perpendicular to the surface. A tangential section through this layer or a surface view of the cell suggests the appearance of a faceted compound eye or of honeycomb. This region is referred to as the 'striated layer.' Between this area and the nuclear wall are three distinctly different types of inclusions within the otherwise homogeneous cytoplasm. The largest and most conspicuous of these structures (v.b.) are vesicular or subvesicular in form, some of them having the appearance of shortened cylinders, possibly open at the ends. In many respects these bodies fulfill the requirements of mitochondria, but, since they fail in certain particulars, they are here designated 'vesicular bodies.' At this period they take the counter stain with Bensley's acid-fuchsin-methyl-green or toluidum blue but may also show a tinge of red. The true mitochondria ( $m i$.) appear as numerous minute granules well scattered throughout the cytoplasm. These granules often show a linear arrangement although they do not fuse to form distinct threads and they take the fuchsin stain. The third type of inclusion is represented by a number of small bodies (e.b.), much larger than the true mitochondria, which are scattered irregularly in the cytoplasm and which take the red of Bensley's stain. These structures vanish from the cytoplasm when the stage represented by figure 9 is reached, but may be seen in the five preceding figures. They are designated 'extra- 
nuclear bodies.' A very distinct 'zwischenkörper' (not shown in figure 9) lies against the wall of the cell, the striated layer here being broken. No centrosomes are visible. The nucleus shows one (sometimes two or more) true nucleoli, and one chromatin nucleolus. At this stage the chromatin is diffuse in arrangement.

Turning now to earlier stages it will be noted that the true mitochondria are distinctly seen in spermatogonial cells before the beginning of the growth period (fig. 1). Indeed, these granules may be distinguished in stages much earlier than those represented. Following the last spermatogonial divisions, the mitochondria aggregate more densely in certain regions of the cell, more particularly against the nuclear wall (figs. 2 and 3 ) where they form one or more deeply staining caps. Thus far in development the cytoplasm appears entirely homogeneous except for the presence of mitochondria. Within the nucleus two nucleoli appear shortly after the end of the last spermatogonial division, and the chromatic material, which is at first diffuse, is more distinctly localized (fig. 3). Figure 4 marks the first appearance of extra-nuclear bodies and vesicular bodies. The former stain red with Bensely's acid fuchsin and are located both within and without the nucleus, many of them being in close contact with the nuclear wall. The latter are now in the form of short fibers, at first very difficult to resolve, but later increasing in bulk and becoming fusiform. They take the counter stain.

In figures $5,6,7$ and 8 , representing successive periods in the growth of the cell, the extra-nuclear bodies become more widely scattered in the cytoplasm. The vesicular bodies increase in number and are changing in form from the fusiform fibers of an earlier stage to the vesicular condition which they will retain until their disappearance. The mitochondria are more numerous and are evenly distributed throughout the cytoplasm. The genesis of the striated outer layer is seen in figure 7. At the end of the growth period (fig. 9) the striated layer has increased in thickness, the mitochondria maintain their uniform distribu- 
tion, the extra-nuclear bodies have disappeared and the vesicular bodies are distinctly vesicular or cylindrical in form.

The details of the process of maturation will not be discussed in this paper since the behavior of the chromatic elements does not bear upon the history of the cytoplasmic inclusions. Immediately before the first maturation division the true nucleolus fragments and its elements disappear. The general arrangement of mitochondria and vesicular bodies during this cleavage is shown in figure 10, and figure 11 represents a spermatid immediately after the completion of maturation. In both maturation divisions mitochondria and vesicular bodies are apparently evenly distributed to the daughter cells.

Very shortly after maturation the spermatid exhibits distinct polarity. The nucleus migrates toward the surface of the cell and certain rearrangements occur among the cytoplasmic elements (fig. 12). The nucleus approaches a point on the surface which is about 30 degrees from the position of the zwischenkörper of the last cleavage. As the nucleus nears the striated layer the striae in its immediate neighborhood disappear. At the same time the mitochondria move in the opposite direction and begin the formation of an aggregate of mitochondrial granules $(a . m)$ at the opposite pole of the cell and somewhat removed from the striated layer. A movement of vesicular bodies toward the nuclear pole, more marked in later stages, begins at this time. Figures 12, 13 and 14 show successive stages in these cytoplasmic rearrangements, leading to the more marked differentiations shown in figures 15 and 16. Figure 15 shows the nucleus in contact with the cell wall which is here entirely without striations. The striated layer is now differentiated into two regions, one around the equatorial region of the cell which exhibits no further modification, and a cap-like area at the pole opposite the nucleus where the striations are shorter. The mitochondrial condensation has resulted in the formation of a massive 'mitochondrial ring' (m.r., fig. 16) which lies slightly below the equator of the cell but which in later stages moves toward the nucleus. Nearly all of the mitochondria of the cell are concerned in the formation of this ring and many of the 
smaller granules fuse together to form large irregular masses. At no time in their history do the mitochondria take their characteristic stains more readily than now, and in the living cell this ring is a most striking object. Figure 15 also shows the manner in which the vesicular bodies approach the nucleus, although, as a matter of fact, they should scarcely be spoken of as vesicles at this time since they are apparently breaking up. Lying mostly between these structures and the mitochondrial ring are now seen certain other substances (o.d.) which appear as homogeneous globules in the living cytoplasm and which, as will later appear, are to be considered as oil droplets.

Between the stage represented by figure 15 and that in figure 19 striking changes occur in the general form of the cell, leading toward the formation of the spermatozoon. The vesicular bodies entirely disappear and the oil droplets increase in number. Little change occurs in the constitution of the mitochondrial ring except a further condensation of its component granules and the migration of the ring as a whole toward the nuclear pole of the cell. The external form of the cell, however, is modified by the invagination of that region which lies immediately opposite the nuclear pole (i.c.), while at the same time the striated layer becomes transformed into a mass of cilia-like threads (c.p.) which project into the invagination cavity. These threads remain short in the region formerly marked by the cap of shorter striations while in the former equatorial region the threads are longer than the original striations (fig. 18). The oil droplets show no change.

From this period until the outer tube of the spermatozoon develops the changes which occur are shown in figures 19, 20,21, 22 , and 23. The mitochondrial ring loses its distinct form and the large granules of which it is composed break up to form smaller granules (figs. 22 and 23). The nucleus moves to one side of the cap of cytoplasm. The cell wall immediately beneath the shorter cilia-like threads thickens and these threads elongate to form a little tuft which projects downward into the invagination cavity (figs. 22 and 23). The opening into the cavity becomes progressively smaller. 
The further history of the metamorphosis of the spermatid into the spermatozoon will be deferred until the latter portion of this paper.

\section{The true mitochondria}

The granular bodies identified as mitochondria are undoubtedly substances of this nature since they fulfill the more generally accepted criteria, although their responses to various methods of technique are not always the same throughout the entire history of the germ cells. The general statement may be made that, up to the time the granules aggregate to form the mitochondrial ring, they are relatively inconspicuous features of the cytoplasm, being difficult to resolve in living cells and staining less sharply with those dyes which are accepted as specific, although there is never any doubt of their presence. Evidently some change occurs in their chemical organization at about the time the mitochondrial ring forms. In stages earlier than this the granules are completely dissolved in fixatives containing a large per cent of acetic acid, but the ring itself, although partly dissolved, is usually not entirely obliterated under such treatment. Somewhat similar variations in the resistance of mitschindria to acetic acid have been noted by Regaud ('08) and by others. With Benda's stain, following Meves' solution, the granules of earlier stages show the violet color but faintly, while the ring takes this stain intensely. In living cells janus green and diethylsafranin stain the ring much more intensely than they do the scattered granules of preceding stages. However, osmic acid darkens the granules and the ring with about equal intensity and the same is true of iron haematoxylin following osmic fixation.

The question of the manner in which the mitochondria of Argas increase in number is extremely difficult to answer. As has already been noted, such an increase probably occurs to some extent throughout the growth of the germ cells, and probably at a rapid rate just before and during the process of maturation. While conclusive evidence is not at hand for absolute statements, my material warrants the belief that the addition 
of new granules is not by formation de novo, but results from the growth and division of preëxisting granules. In stages represented by figures $8,9,10$ and 11 the mitochondria are of different sizes and the larger granules show irregularities in shape which might be interpreted as indicating constrictions which would lead to division. Moreover, the linear arrangement of the granules might be interpreted as representing series of granules which had been produced by division of one or more original granules. However, the granules are so minute at this time that one is not justified in making dogmatic statements. Most of the mitochondria of the cell are concerned in the aggregation which forms the ring. Some, however, remain scattered in the cytoplasm. The disintegration of the ring, shown in figures 21, 22 and 23, results from the splitting up of mitochondrial masses, although the resulting bodies are not as small as the granules which originally formed the ring.

\section{Extra-nuclear bodies}

The various accounts and discussions which have appeared in recent years relative to the nature and, indeed, the reality of substances in the form of globules, granules, exudations, etc., supposedly emitted from the nucleus of various animal cells, give particular interest to the presence of similar structures in the spermatocytes of Argas. It is not my purpose to discuss the literature of this subject here, but merely to state the facts in this particular case with a few brief comparative references. The structures which are designated extra-nuclear bodies (e.b.) appear soon after the stage represented by figure 3 and they vanish shortly before maturation. Figure 3 may be considered as representing a 'pre-emission' stage. At this time an acidstaining nucleolus, a basic-staining nucleolus and the chromosomes are the only structure within the nucleus which react to dyes, while within the cytoplasm the mitochondria and the zwischenkörper take definite stains. With the continued growth of the cell small bodies, globular rather than granular, appear within the nucleus and they are also seen within the cytoplasm, 
either applied to the nuclear wall or in its immediate neighborhood, and they are later more widely scattered in the cytoplasm. A glance at figures 4 to 8 will show the positions occupied by these bodies. Before the time of maturation they entirely disappear. From the morphological standpoint the evidence is very conclusive that these bodies arise in the nucleus, pass to its periphery, reach the nuclear membrane, and in some form and in some manner pass through the wall, later to become free in the cytoplasm. The passage of these substances through the wall has not been observed, but in several cases the nuclear wall is bent outward in tront of the body and somewhat modified in texture, but these conditions may represent artefacts.

Regarding the nature of these bodies the following suggestions are offered. They do not represent the 'extranuclear chromatin' of Schaxel ('11) and others, for their staining reactions do not suggest chromatin, nor are they similar to the pseudochromatin granules of Beckwith ('14) either in point of origin or in microchemical reactions. In many particulars these bodies recall the nuclear globules of Beckwith, for they bear like positional relationships, react similarly to Benda's stain and, after a brief existence, they disappear from the cytoplasm. They are not mitochondria and appear to bear no definite relation to the mitochondria, for acid fixatives such as Carnoy's fluid have no effect upon them, while dissolving all of the mitochondria in the cell. Moreover, the mitochondria are already present in the cell when these bodies appear. The extra-nuclear bodies are present in the cytoplasm when the first rudiments of the vesicular bodies are becoming visible, but they are not transformed into these latter structures, for the vesicles are also dissolved by strong acetic solutions; nor is there any morphological evidence of such a transformation. That the presence of extra-nuclear bodies in the cytoplasm gives the chemical stimulus necessary for the formation of the vesicular bodies, is possible but scarcely probable.

The cellular structure with which the extra-nuclear bodies appear to be most closely related in microchemical reactions is the true nucleolus or plasmosome. After Benda's stain the 
extra-nuclear bodies correspond in color to the plasmosome and do not stain like the chromatin, and with Bensley's acid-fuchsinmethyl-green (or other counter stain) they and the nucleolus take the brilliant red of the acid dye. One is led to the conclusion that these extra-nuclear bodies represent products of nuclear activity similar to those substances found in the plasmosome and that they are of little further significance in the economy of the cell, being thrown out into the cytoplasm where they are later dissolved and absorbed after the manner in which the plasmosome itself disintegrates at the time of maturation.

\section{Vesicular bodies and oil drops}

As has been noted, the vesicular bodies are first seen during the early growth stages, having the form of elongated, fusiform fibers which appear among the mitochondria, both where these granules are thickly aggregated and where less concentrated. There is no evidence that the fibers arise directly from mitochondria as described by Sokolow ('13) for structures of somewhat similar form in the spermatocytes of the scorpion, but they appear to arise de novo in the cytoplasm. There is some evidence that the fibers may multiply by transverse fission, although this is doubtful. The metamorphosis of a fiber into a vesicle is accomplished by the thickening of the fiber in the middle, followed by the appearance of a cavity in the thickened portion, which gradually increases in extent until a distinct vesicle is formed (figs. 5, 6 and 7). When the stage represented by figure 8 is reached, all of the fibers have been transformed into vesicles and some of the vesicles are cylindrical in shape with thinwalled ends. Apparently these bodies increase in number during the remaining period of growth but no evidence can be presented as to the exact method of multiplication.

Following maturation, the vesicular bodies take part in the polarization of the spermatids by separating from the true mitochondria and moving toward the nucleus. Figures 12 to 15 illustrate these rearrangements and they also show the beginnings of certain degenerative processes which lead to the disinte- 
gration of the vesicles (figs. 17 and 18). These changes are marked by the breaking of the walls of the vesicles or cylinders (so that sections of these bodies are now sickle-shaped or threadlike) and by their dissolution. As the vesicles degenerate the cytoplasm in which they lie shows the presence of rounded homogeneous globules or droplets (o.d.). The point of origin and the position of these globules strongly suggest a causal relationship between their appearance and the disintegration of the vesicular bodies. However, it can not be urged that any single globule is formed directly from a particular vesicle, for the globules are larger than the vesicles. The substance comprising the globules is of an oily or fatty nature, if microchemical tests may be relied upon, for the globules become blue when the cells containing them are placed in a modified Lock's solution to which is added brilliant cresyl blue in proportions of $1: 50,000$, while other elements of the cell remain unstained.

How shall the vesicular bodies be classified? Apparently they are closely allied to true mitochondria, although they fail to conform in all particulars to the criteria employed in identifying typical mitochondria. They agree with mitochondria in that (1) they are dissolved in acetic acid; (2) they are not unlike mitochondria in form; (3) they show certain typical mitochondrial reactions to dyes. With Bensley's stain the vesicles take the fuchsin but slightly, and the same is true of the violet of Benda's stain. In the living cell the vesicles are but lightly stained with janus green, but this is also true of the mitochondria before they aggregate to form the mitochondrial ring, nor are the true mitochondrial granules of the spermatogonia and spermatocytes at all well differentiated with Benda's stain. As has already been noted, the responses of mitochondria to microchemical tests apparently differ. at different periods in the life of the cell which contains them. The granules which are undoubtedly mitochondria pass from a state of relative indifference to certain supposedly specific stains (as crystal violet and janus green) to a condition in which these stains are taken with avidity. The vesicular bodies may be thought of as mitochondrial in nature but differing from the granules in this particular, 
that they disintegrate before reaching a stage in chemical composition which corresponds to that attained by the true mitochondria at the time they form the ring. The association of fat globules with the vesicular bodies at the time of their disintegration also suggests an identity with typical mitochondria, if the results and conclusions of Dubreuil ('11, '13) are accepted, for he derives fat droplets very directly from mitochondria, and a similar relation is suggested by Fauré-Fremiet ('10) and others for certain types of mitochondria. On the other hand, the work of the Lewises ('15) throws doubt upon such a relationship, although the possible influence of mitochondria in fat formation is not denied.

Finally the possibility should be considered that the vesicular bodies may represent intra-cellular parasites. It is claimed by Hindle ('11) that the organism (Spirochaeta gallinarum) which produces spirochaetosis in fowls, passes through a stage in its life history in which the spirochaete breaks up to form many small, rounded bodies which he speaks of as 'coccoid bodies.' These bodies are found in various tissues of the tick but more particularly in the cells of the Malpighian tubules and in the ovary. Marchoux and Couvy ('13) deny that this relationship exists between the so-called 'coccoid bodies' and the spirochaete and they claim that these bodies are normally present in the tissue cells of species of ticks which do not carry protozoan organisms. They are unable to decide upon the nature of these structures, although, among other possibilities, they suggest a relationship to mitochondria. A thorough study of cells from the Malpighian tubules, salivary glands, crop and intestine of Argas leads me to the conclusion that none of the cytoplasmic inclusions found in the cells of these organs is to be identified as at all similar in structure or behavior to the vesicular bodies of the germ cells. In the spermatocytes and spermatids of other species of ticks which I have examined (Dermacentor variabilis, Ornithodoros turricata, Rhipicephalus sanguineus) are found inclusions entirely homologous with the vesicular bodies of Argas. The manner in which the vesicles appear at a particular stage in the history of the germ cells, and the way in which they pass 
through a series of definite modifications at all times parallel with certain developmental stages of the cell, argues strongly against a parasitic relation. Moreover, although Spirochaeta gallinarum is a common blood parasite of the fowl and its tick in many parts of the world, it has never, to my knowledge, been observed in the blood of chickens or in ticks living in the United States. The evidence seems conclusive that the vesicular bodies are component parts of the germ cells and are not of external origin.

\section{FORMATION OF THE SPERMATOZOA}

The preliminary steps in the metamorphosis of the spermatid have already been indicated. The stage shown in figure 23 is produced by the invagination of that side of the cell which lies opposite the nucleus (fig. 19), and this invagination marks an important phase in the series of transformations which eventually produce the highly specialized spermatozoon of the tick. These processes begin with the extension of the invagination cavity, and soon this cavity with its surrounding walls is converted into a hollow tube (o.t.) which rapidly extends outward from the nuclear region of the cell until it reaches the relatively enormous length shown in figure 27. This tubular outgrowth is designated the 'outer tube.' In the early stages of its development the cilia-like remains of the striated layer of the spermatid project into the cavity of the tube, but these structures degenerate later and form a gelatinous mass which partly fills the tube. The shorter filaments which are grouped to form a tuft at the bottom of the tube retain their individuality somewhat longer.

While the outer tube is developing, certain changes are occurring at the nuclear end of the elongating cell. The mitochondria break up into yet finer granules which collect around the proximal end of the tube (fig. 24). The cytoplasm opposite the base of the tube now flows outward and somewhat to one side, at first in the form of a blunt projection which becomes more extended (fig. 25) and finally takes the form of a distinct finger-like process (f.p.) as shown in figures 26, 27 and 28. During the period represented by figures 23 to 27 the nucleus also undergoes exten- 
sive alteration, becoming pear-shaped in form and later more elongated. The chromatin, which heretofore has been diffuse, aggregates into threads which stain intensely with nuclear dyes. The nucleus now orients itself in relation to the finger-like process in such a manner that the more pointed end projects into the basal portion of this process.

During the course of its formation the outer tube is bent upon itself and coiled around its basal region although the arrangement of the loops is not always similar to that shown in figure 27. At this stage the developing spermatozoa are packed closely together, and only in teased preparations and in smears can their individuality be distinguished. As the tube grows outward it is surrounded by a gelatinous envelop (g.e.) which increases in amount as the tube develops and apparently serves to hold the coils of the tube together. This enveloping gelatinous mass persists until the spermatozoa are near the completion of their metamorphosis.

Figures 27 and 28 picture the genesis of a structure designated the 'inner tube' which arises within the proximal end of the outer tube. As will be recalled, this region of the original invagination is marked by a cluster of cilia-like processes which extend into the cavity. Even in the stage represented by figure 21 the surface of the cell is here thickened. In later stages this thickening becomes more extensive and finally develops into a deeply staining ring-like elevation which projects from the bottom of the outer tube and which bears a circlet of delicate threads (figs. 24,25 and 26).

At about the time the outer tube reaches a condition of maximum extension this ring begins to project into its cavity (fig. 27). This is the beginning of the formation of the inner tube (i.t.) which continues to advance within the outer, as shown in figures 28 and 29, until both tubes reach approximately the same length (fig. 30). As a matter of fact the inner tube grows at the expense of the outer, for during its formation the length of the developing spermatozoon is reduced about one-half, as will be seen from a comparison of figures 27 and 30 , and as is shown in text-figure 1 . As the head of the inner tube advances, 
the substance which forms the walls of the proximal half of the outer tube is drawn into the basal region of the inner tube. From the very beginning of its formation the inner tube contains mitochondria, and as its growth progresses it draws into itself all of the mitochondria of the cell (figs. 27, 28, 29, and 30).

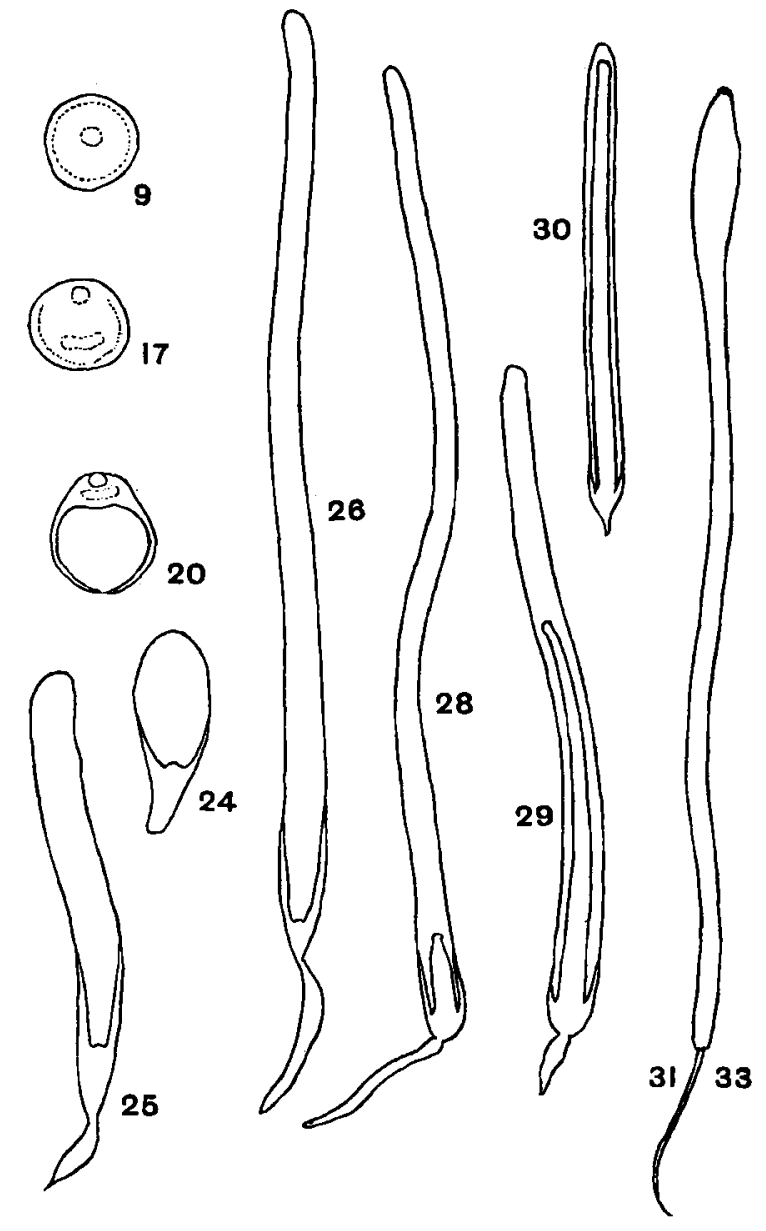

Text fig. 1 Outline drawings of illustrative stages in the formation of the spermatozoon, showing its relative form and size at different periods of development. All stages here represented are from camera lucida drawings of living material at the same magnification. The numbers refer to approximately similar stages shown in the plates. 
The mitochondria are densely collected at the outer or distal end of the inner tube and when the tube is fully formed all of these granules lie in its distal third. Between the stage shown in figure 27 and that of figure 28 the cilia-like processes upon the tip of the inner tube vanish, and in their place is a clear hemispherical vesicle which may possibly represent the substance formerly seen in these processes.

During the growth of the inner tube the nucleus migrates extensively. As shown in figure 28 it still lies at the bases of the two tubes, but shortly afterwards it moves around to the outer surface of the outer tube and begins to travel along this tube toward the opposite end. The outer tube is at this time covered with a gelatinous sheath through which the nucleus moves. By the time the inner tube has reached its full extension the nucleus lies opposite its distal end, and upon the outer surface of the outer tube (fig. 30). While these rearrangements are occurring, the finger-like process progressively shortens (figs. 29-30), and some of the substance of which it was composed is apparently absorbed into the basal ends of the two tubes.

In the condition shown in figure 30 the spermatozoa leave the male tick and their development is completed within the genital ducts of the female, where they are at first packed together in sac-like spermatophores, and later lie freely in the oviduct. Figure 31 represents a spermatozoon from a spermatophore sac. By comparison with figure 30 it will be noted that the older spermatozoon is now in the form of a single tube with the mitochondria at one end and the nucleus at the other, and that its total length is about twice that of the spermatozoon shown in figure 30. See also text-figure 1. In accomplishing this metamorphosis the mitochondria-filled end of the inner tube pushes through the distal end of the outer tube (at $a$, fig. 30) and continues its advance, while the outer tube slips backward along the outer surface of the inner tube until at last outer and inner tubes are merged into one continuous structure. As a result of this process the outer tube is turned completely inside out, and the end which was formerly around the mitochondria-bearing end of the inner tube now lies at the opposite end of the spermatozoon 
(fig. 31). The nucleus retains contact with the original outer surface of the outer tube and is carried to the opposite end of the spermatozoon, where it now lies within the tube. The remnant of the finger-form process and the gelatinous envelop of the original outer tube are also carried within the tube as it slips backwards and turns inside out. Within the nuclear end of the completed tube, as represented in figure 31, is a long, somewhat coiled, flagellum-like structure $(f)$ which extends downward in the tube from the mass of protoplasm which surrounds the nucleus.

The final steps in metamorphosis occur just before the spermatozoon leaves the spermatophore sac and immediately thereafter as it lies within the oviduct. At this time the flagellum pushes past the nucleus and outward through the open end of the tube (fig. 32) and soon is completely protruded (fig. 33). The nucleus also slips out of the tube and lies imbedded in the base of the flagellum. The opposite or mitochondria-bearing end of the sperm tube now changes somewhat in form. It becomes flattened and ridged as shown in figure 34 and a circlet of short processes appears around the vesicle which crowns the tip-end of the tube.

The extremely bizarre form of the spermatozoon of the tick makes difficult the task of homologizing its parts with those of other spermatozoa. In the case of Argas about the only landmark which one can use is the nucleus, for no centrosomes are visible at any stage of spermatogenesis, and the highly complex processes of metamorphosis obliterate or mask the characteristic features of typical spermatozoa. Using the final position of the nucleus as a guide, one is led to the conclusion that the morphological head of the spermatozoon is that end of the completed tube in which the nucleus lies. One would naturally expect that this would be the forward end of the moving spermatozoon but such is not the case. The living spermatozoon of Argas does not exhibit locomotion until it is completing its development in the spermatophore sac in the oviduct of the female, at which time it moves with the mitochondria-bearing end in advance. This observation is in harmony with the conclusions 
of Samson ('09) for the spermatozoa of Ixodes and Ornithodoros. Samson also holds the view here expressed, that the nucleus marks the morphological head of the mature sperm tube, basing her conclusions upon the identification of the nucleus by its staining reactions and upon her studies of fertilization. After many fruitless attempts she succeeded in observing the process of fertilization in Ixodes and she states that it is the nuclear end which first penetrates the egg. I have endeavored in vain to secure similar data for Argas.

If it be granted that the nucleus marks the morphological head of the tick spermatozoon one might infer that the protoplasmic process (flagellum), which pushes outward from the nuclear end of the tube at the time the spermatozoon reaches maturity, is homologous with the acrosome of the other spermatozoa. The origin of this structure is somewhat uncertain since the cytoplasm of which it is composed takes no specific dye, but it may not be too much to infer that it is formed largely of the substance of the conspicuous finger-shaped process which is so prominent a feature of the earlier stages shown in figures 25 to 29. This process does not migrate along the primary tube with the nucleus and, although it becomes reduced in size and relatively inconspicuous by the time the spermatozoon is transferred to the female, it yet persists and must later be drawn into the nuclear end of the completed tube when the outer tube has slipped completely back over the inner.

The exact manner in which the spermatozoon of the fowltick accomplishes locomotion is difficult to determine. As the mitochondria-bearing end advances, its vesicular tip contracts and expands in a peculiar manner and the processes surrounding the vesicle are also in motion. The mitochondria within the tube lie near the surface and the granules are arranged in linear series, giving this portion of the tube a longitudinally striated appearance. One gains the impression from an examination of living spermatozoa that the mitochondria represent contractile elements which are responsible for the movements which this end of the spermatozoon exhibits. A relation between mitochondria and motor organs was long ago suggested by 
Benda ('99), and more recently Duesberg ('10) has advanced the idea that the myofibrils of striated muscle are of mitochondrial origin. As has been noted, mitochondria are found only in the end of the sperm-tube which shows active movement.

Samson's ('09) accounts of the metamorphosis of the spermatozoa of Ixodes ricinus and Ornithodoros moubata are in many respects parallel to that of Argas as here related. Starting with a very brief description of the spermatid of Ornithodoros (illustrated by two figures) she follows the formation of both inner and outer tubes and notes the manner in which the nucleus migrates along the outer surface of the outer tube. She also notes, but does not represent in her figures, the presence of a 'finger-förmigen Plasmafortsatz,' the fate of which is left in doubt. The later stages in metamorphosis are taken from the history of the spermatozoon of Ixodes. The mature spermatozoon is figured and described, and the statement is made that in the processes of its formation the head of the inner tube pushes its way through the outer, but the manner in which this evagination leads to the formation of a single tube is not definitely indicated. An apical organ is described and its origin from material within the completed tube is suggested together with the relation of this body to the nucleus. The presence of a flagellum-like structure ('geissel') within the nuclear end of the tube is indicated, but no stage is figured in which this flagellum projects from the tube as it does in Argas, although supposedly mature spermatozoa of both Ixodes and Ornithodoros are shown. Samson reviews the work of Christophers, Bonnet and Nordenskiöld, pointing out some of their errors, to which further reference will not be made in this paper.

\section{SUMMARY AND CONCLUSION}

In the spermatocytes of Argas miniatus toward the end of the growth period three distinct types of cytoplasmic inclusions may be recognized. These are designated true mitochondria, extra-nuclear bodies and vesicular bodies. The outer surface of the cytoplasm is differentiated to form a honeycomb-like 
layer marked by striations which run perpendicular to the surface.

The extra-nuclear bodies appear early in the growth period. They are first seen within the nucleus, later pass through the nuclear wall, and finally become widely scattered in the cytoplasm, where they are dissolved and absorbed before the time of maturation. Their behavior and staining reactions suggest that these bodies are similar in nature to the plasmosome or true nucleolus.

The vesicular bodies are formed de novo in the cytoplasm at about the time the extra-nuclear bodies appear, but no apparent relationship exists between the two. When first seen they appear as fusiform fibers but as they increase in number the fibers open out to form vesicles (v.b., fig. 5). These bodies are evenly distributed in the cytoplasm until after the formation of the spermatids, when they collect near the nucleus at one side of the cell. Here they gradually disintegrate and, as they are breaking down and disappearing (fig. 15), droplets of a fatty nature (o.d.) are deposited in the cytoplasm which surrounds them. The vesicular bodies are considered as mitochondrial in nature for they fulfill several, although not all, of the tests employed in determining mitochondria.

The true mitochondria are present in the youngest spermatogonia examined, and they persist, with certain modifications of arrangement and form, throughout the entire history of the developing spermatozoon. In the young spermatids (fig. 13, a.m.) mitochondria begin to collect at the side of the cell opposite the nucleus, where many of the granules fuse together and form a massive ring (figs. 15 and 16, m.r.). Later, when the mitochondrial ring breaks up (fig. 23) the granular mitochondria are not widely scattered but are carried in a mass to a particular region of the forming spermatozoon.

The transformation of the spermatid into the spermatozoon is initiated by (1) the migration of the nucleus to one side of the cell, (2) the formation of the mitochondrial ring (3) the movement of the vesicular bodies toward the nucleus and their later disintegration, and (4) by the disappearance of the outer striated 
layer from the surface of the cell near which the nucleus lies. See figures 12 and 15 . Following these rearrangements, the surface of the cell opposite the nuclear pole is indented and the bounding walls of the invagination cavity thus produced (fig. 19) grow outward (fig. 23) to form a long tube which is designated the 'outer tube' of the developing spermatozoon (fig. 24 and following). Into this tube is carried the material which formed the outer striated layer of the spermatocytes and spermatids. The striations now take the form of cilia-like processes (although they are not mobile), which later dissolve and form a gelatinous mass within the tube. However, a tuft of these threads at the base of the tube persists for a longer period (figs. $24,25,26,27)$. At the opposite or nuclear pole of the cell a finger-form process (f.p.) develops and the nucleus migrates toward the base of this process, at the same time changing in form (figs. 24 and 26 ).

The next step in metamorphosis is the formation of the "inner tube' which develops within the outer tube (figs. 27, 28, 29 and 30). The inner tube grows at the expense of the outer, for when both are of nearly equal length, the length of the entire spermatozoon is reduced by one-half. The nucleus migrates through the gelatinous layer along the outer side of the outer tube (fig. 29) and eventually lies opposite the distal ends of both tubes (fig. 30). All of the mitochondria of the cell are drawn into the distal end of the inner tube. The finger-form process is reduced in size.

While the spermatozoon is in the spermatophore sac within the genital ducts of the female, the distal end of the outer tube forces its way out of the inner tube (at $a$, fig. 30), and the outer tube slips backward along the inner. With the completion of this evagination process, the two tubes form one continuous sperm-tube, one-half of which represents the inner tube and the other half the original outer tube turned inside out (fig. 31). The mitochondria now lie at one end of the spermatozoon, within the original inner tube, while the nucleus, which has retained contact with the original distal end of the outer tube and has been carried backward with it, now lies within the end 
of this tube and at the opposite end of the continuous spermtube. A flagellum-like process $(f)$, which is probably derived from the finger-form process, lies within the nuclear end of the tube.

Metamorphosis is completed by the protrusion of the flagellum from the nuclear end of the spermatozoon (fig. 33) and by the formation of a circlet of mobile processes at the opposite or mitochondria-bearing end of the sperm. In locomotion the end of the spermatozoon which bears the mitochondria goes first and it would appear that the contractile elements which make locomotion possible are of mitochondrial origin.

The end of the spermatozoon which bears the nucleus is interpreted as the morphological head, and the flagellum (which is not mobile) probably represents the acrosome of more typical spermatozoa. 


\section{BIBLIOGRAPHY}

BECKwith, C. J. 1914 The genesis of the plasma-structure in the egg of $\mathrm{Hy}$ dractinia echinata. Jour. Morph., vol. 25.

Benda, C. 1899 Weitere Beobachtungen über die Mitochondria, etc. Verh. d. Phys. Ges. Berlin. 1903 Die Mitochondria. Ergebn. Anat. und Entwickl., Bd. 12.

Bishopp, F. C. 1913 The fowl tick. U. S. Dept. of Agriculture, Bur. Entomology, Circ. No. 170.

Bonnet, A. 1907 Recherches sur l'anatomie comparée et le developpement des Ixodides. Ann. de l'Univ. de Lyon, Nouv. Ser., I, Sciences, Fasc. 20.

Christophers, S. R. 1906 The anatomy and histology of ticks. Scientific Memoirs by the Officers of the Medical and Sanitary Department of the Government of India.

CowDry, E. V. 1912 The relations of mitochondria, etc. Intern. Monatsschr. f. Anat. u. Phys., Bd. 29.

1916 The general functional significance of mitochondria. Am. Jour. Anat., vol. 19.

Dubreurl, G. 1911 Transformation directe des mitochondries et des chondriocontes en graisse dans les cellules adipeuses.

1913 Le chondriome et le dispositif de l'activite secretoire, etc. Arch. d. Anat. micr., T 15.

Duesberg, J. 1911 Plastosomen, apparato reticulare interno und chromidial apparat. Erg. d. Anat. u. Entwick., Bd. 20.

Faure-Fremiet, E. 1910 Etude sur les mitochondries des Protozoaries et des cellules sexuelles. Arch. d. Anat. micr., T 11.

Hegner, R. W. 1914 The germ cell cycle. New York.

Hinde, E. 1911 On the life cycle of Spirochaeta gallinarum. Parasitology, vol. 4.

Lewis, W. H., and Lewis, M. R. 1915 Mitochondria (and other cytoplasmic structures) in tissue cultures. Am. Jour. Anat., vol. 17.

Marchou, E. et Couvr, L. 1913 Argas et Spirochetes. Ann. de l'Institute Pasteur, T 27.

Meves, Fr. 1908 Die chondriosomen als Träger erblicher Anlagen. Arch. f. mikr. Anat., Bd. 72.

1910 Uber Strukturen in den Zellen, etc. Arch. f. mikr. Anat., Bd. 75.

NoRDENSKIÖLD, E. 1907 Zur Spermatogenese von Ixodes reduvius. Zool. Anz., Bd. 34.

Regaud, Cl. 1908 Sur les mitochondries, etc. C. rend. Soc. Biol., T. 65. 1911 Les mitochondries. Rev. de Med., T 31.

Samson, Katharina 1909 Zur Spermiohistiogenese der Zecken. Berlin Sitz.Ber. Ges. natf. Freunde.

Schnxel, J. 1911 Plasmastructuren, chondriosomen und chromidien. Anat. Anz., Bd. 39.

Sokolow, I. 1913 Untersuchungen über die spermatogenese bei den Arachniden. I über die spermatogenese der Skorpione. Arch.f. Zellforsh., Bd. 9. 
PLATES 


\section{EXPLANATION OF PLATES}

All figures are drawn to the same scale except figure 29 , which was drawn to one-half the scale of the others. The drawings were all made at table level with a Leitz camera lucida and with the use of Leitz ocular 6 and Leitz $2 \mathrm{~mm}$. apochromat N. A. 1.32 objective, draw tube set at $152 \mathrm{~mm}$. With one-third reduction in reproduction the magnification is thus 926 diameters (except figure 29). At all stages in the devclopment of the spermatozoon size variations may be noted. In most cases an average-sized representative of a particular stuge has been selected, but the figures will show some exceptions to this practice. Only those cytoplasmic constituents which are essential to the discussion are represented in the drawings; otherwise distinetions could not be expressed satisfactorily with line drawings. Unless otherwise indicated the drawings are made from sections 2 to 5 in thickness.

\section{PLATE I}

\section{EXPLANATION OF FIGURES}

1 Spermatogonial cell in division. The small dots in the cytoplusm in this and the figures which follow represent mitochondria.

2 Two cells at the beginning of the growth period. The nuclear cap is formed of mitochondria.

3 Three growing cells from a testicular cyst.

4 Farly growth stage showing genesis of extra-nuclear bodies (e.l.) and vesicular bodies (y.b.).

5, 6, 7 and 8 Successive stages in the growth period. Figure 7 shows the first evidence of the striated layer (s.l.).

\section{ABBREVIATIONS}

a.m., aggregating mitochondria

c.p., cilia-like processes

e.b., extranuclear bodies

f., flagellum

f.p., finger-form process

g.e.. gelatinous envelop

i.c., invagination cavity

i.t., inner tube

$m i$. , true mitochendria m.r., mitochondrial ring

$n .$, nucleus

o.d., oil droplet

o.t., outer tube

$p l$, plasmosome

s.l., striated layer

$v . b$, vesicular bodies

$z .$, zwischenkörper 
GERM CELLS OF A RGAS

PLATE 1

v. B. CASTEEL
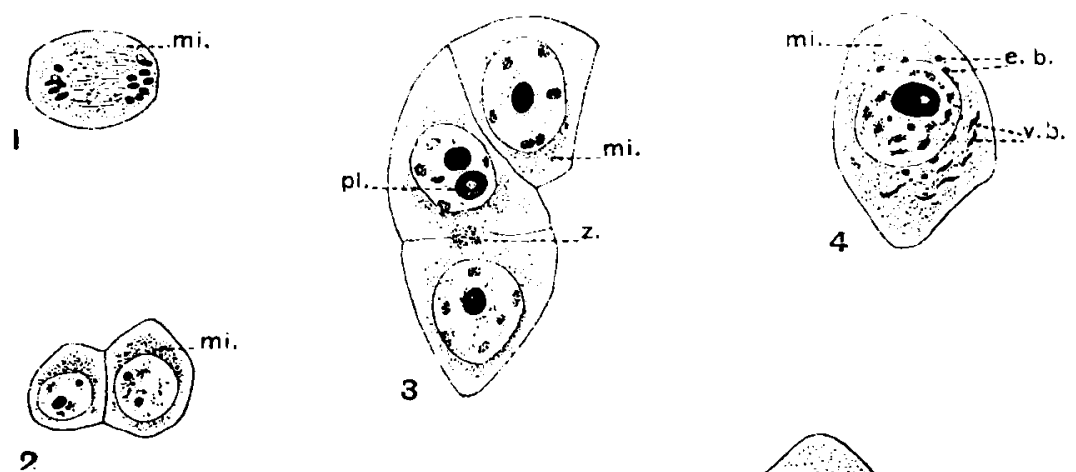

?.
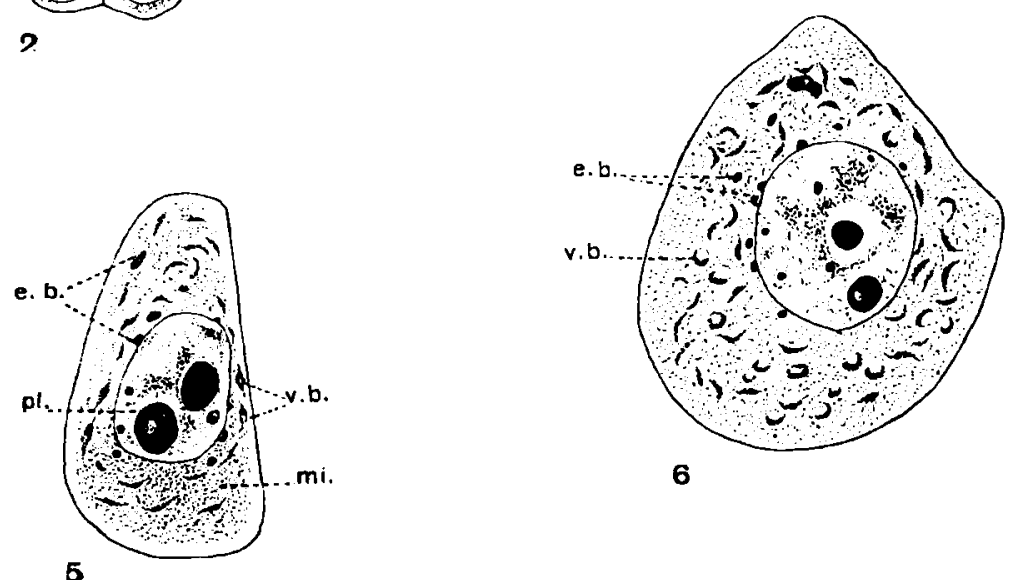

5
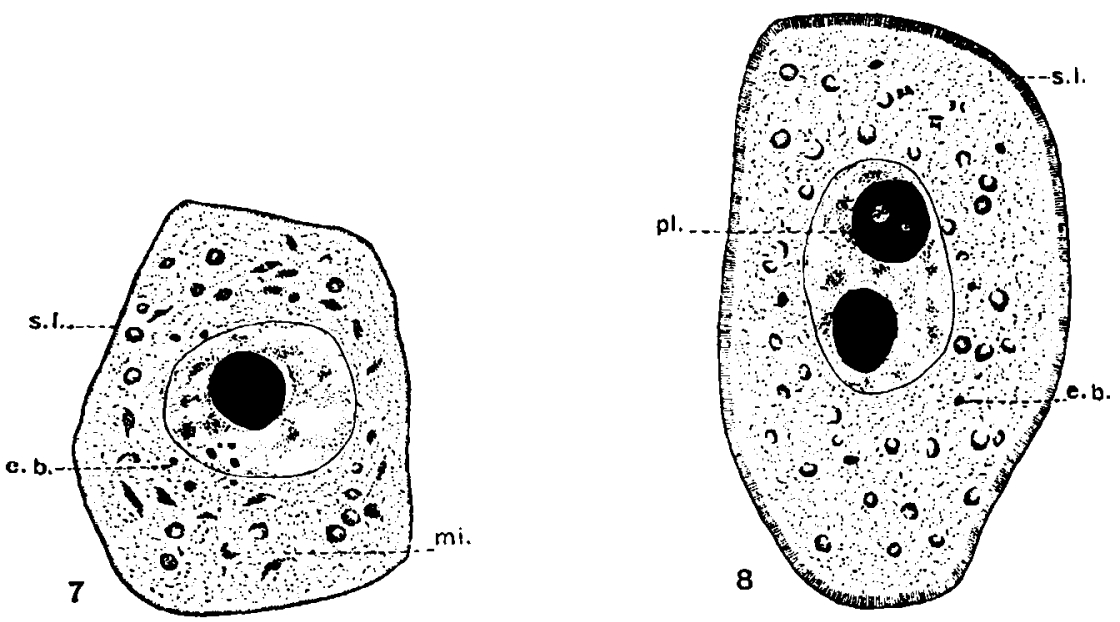

669

JOURNAL ON MORPHOLOGY, VOL. 28, NO. : 


\section{PLATE 2}

explanation of Figures

9 Primary spermatocyte just before division.

10 First maturation division.

11 Spermatid immediately after completion of second maturation division.

12 Spermatid showing beginning of polarization of the cell as expressed by the aggregating mitochondria $(a . m$.) and by the manner in which the striated layer is vanishing from the region of the cell which the nucleus is approaching. 13 and 14 Spermatids in which the process of polarization is continued. 

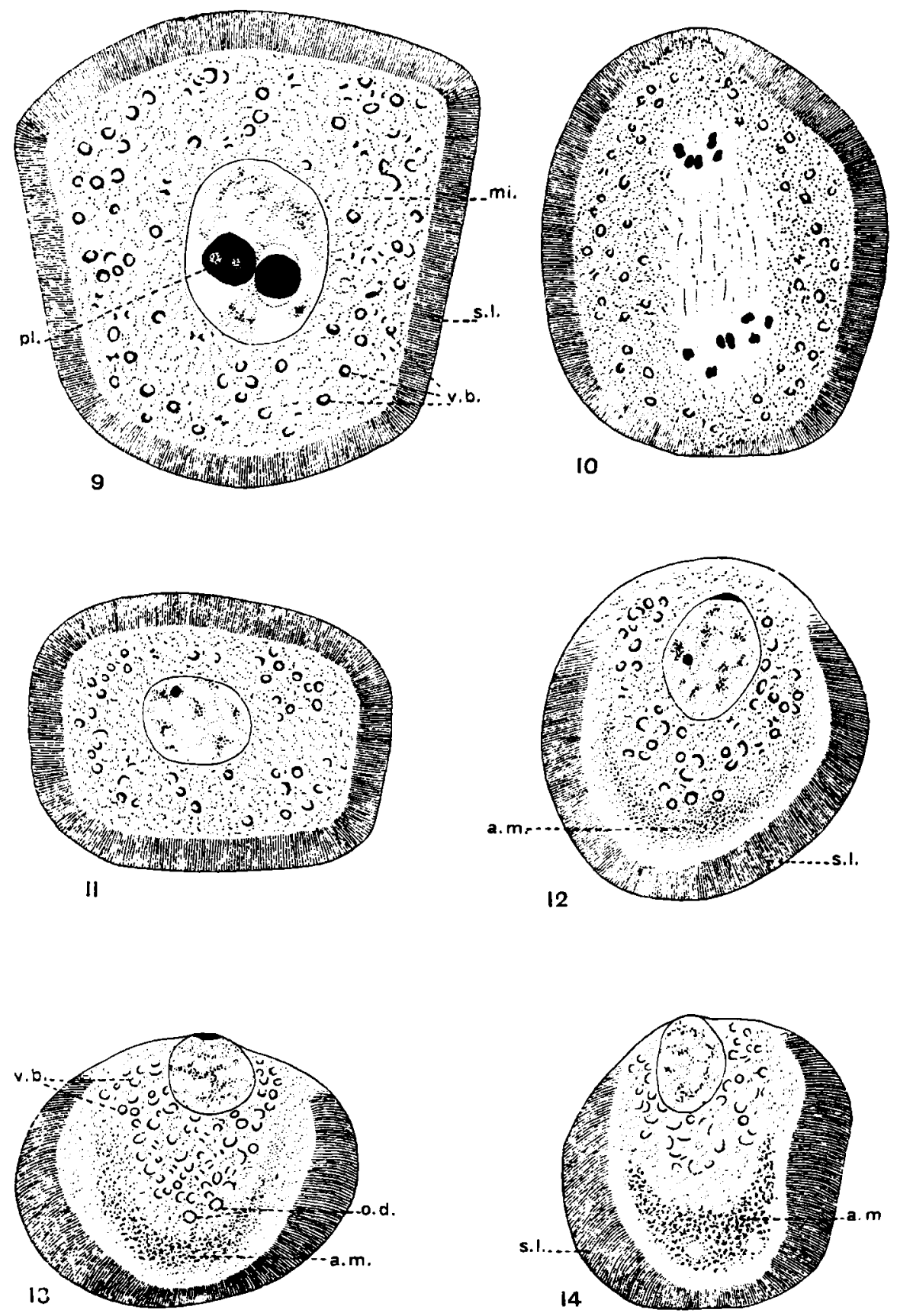


\section{PLATE 3}

EXPLANATION OF FIGURES

15 Spermatid exhibiting differentiation of the striated layer into two regions, disintegration of vesicular bodies, deposition of oil droplets (o.d.) and the completion of the mitochondrial ring (m.r.).

16 Section of the cell perpendicular to that of figure 15, showing the form of the mitochondrial ring.

17 and 18 Two stages preceding the invagination of the spermatid. The vesicular bodies vanish, additional oil droplets appear and in the striater layer the formation of cilia-like processes (c.p.) begins.

19 and 20 Two stages in the development of the invagination cavity (i.c.). 
D. B. CASTEEL
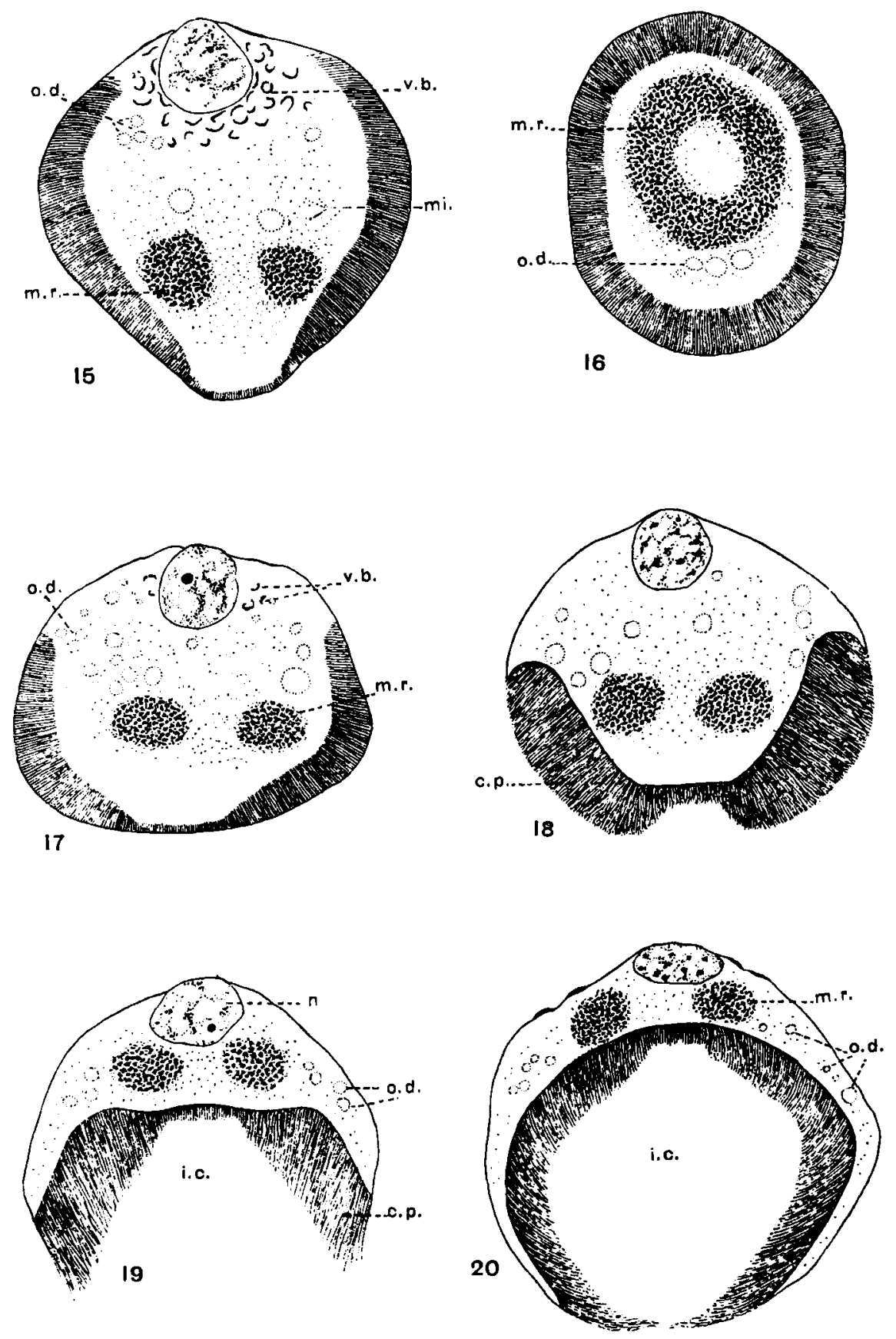


\section{PLATE 4}

\section{EXPLANATION OF FIGURES}

21 and 22 Two stages representing the enlargement of the invagination cavity and the breaking up of the mitochondrial ring.

23 The beginning of the elongation of the invagination cavity.

24 The invagination cavity is clongating to form the outer tube (o.t.) of the spermatozoon, the nucleus is changing in shape and the finger-form process (f. p.) is appearing. 

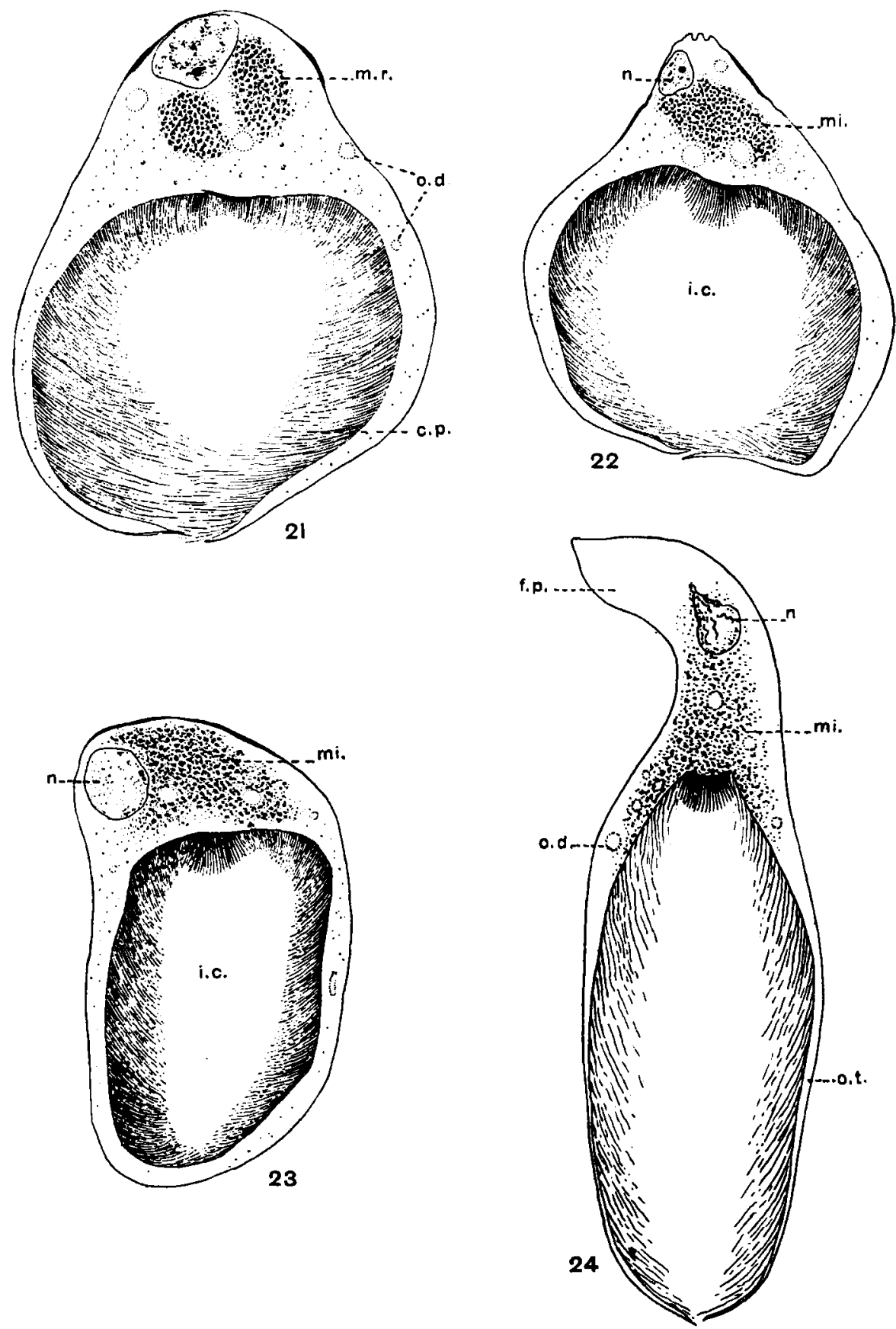


\section{PLATE 5}

\section{EXPLANATUON OF FIGURES}

25 Proximal end of a developing spermatozoon. The finger-form process is taking shape.

26 Proximal end of a developing spermatozoon. The finger-form process has reached its maximum size. The cilia-like fibers within the inner tube have largely disintegrated, except those at the bottom of the tube.

27 Entire young spermatozoon from smear preparation, showing the long, coiled outer tube somewhat surrounded by the gelatinous envelop (g.e.) and the beginning of the formation of the inner tube $(i . t$.$) with the mitochondria flowing$ into it. 
GERM CEIISS OL ARGAS

PLATE 5

D. H. CA TIEEL

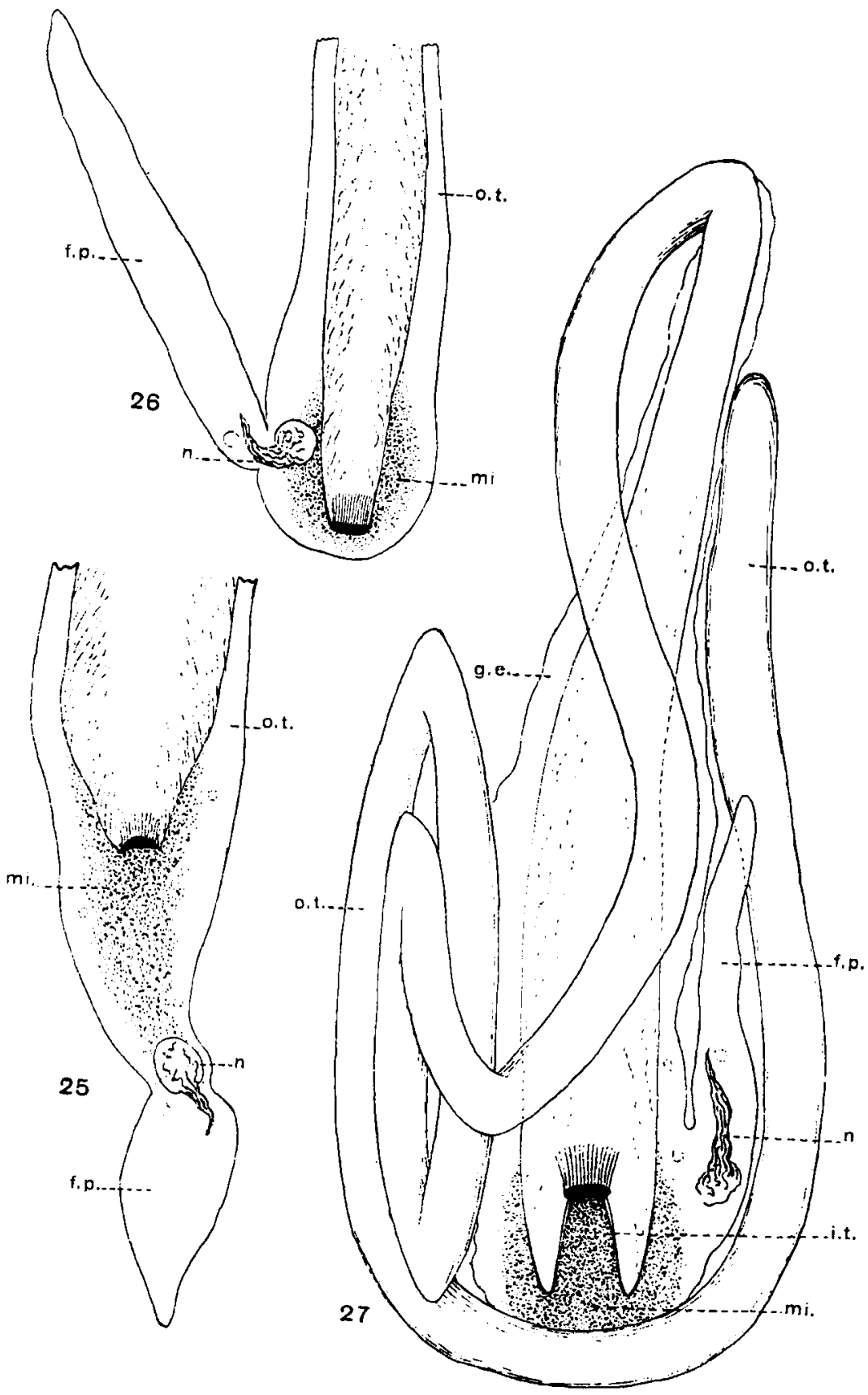


PLATE 6

EXPLANATION OF FIGURES

28 See plate 7.

29 Young spermatozoon from smear preparation, drawn to one-half scale of the other drawings. The head of the inner tube has advanced half way down the outer tube. The elongated nucleus is migrating through the gelatinous envelop toward the distal end of the outer tube. The finger-form process has diminished in size.

30 Spermatozoon from smear preparation in the condition in which it is transferred in the spermatophore from the male to the female tick. Both the nucleus and the mitochondria-bearing end of the inner tube lie near the distal end of the outer tube. The innei tube will later break through the outer at the point $a$. 
GERM CELI.S OF ARGAS D. B. CASTEEL

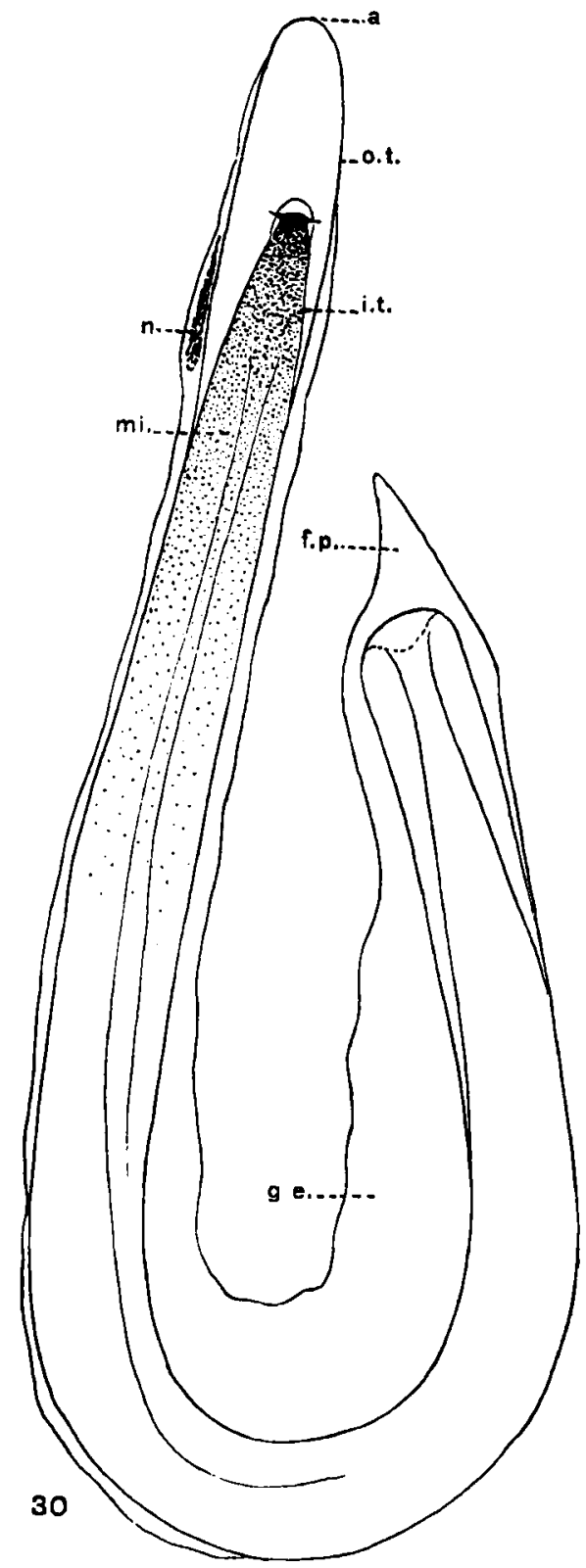

PIATE 6

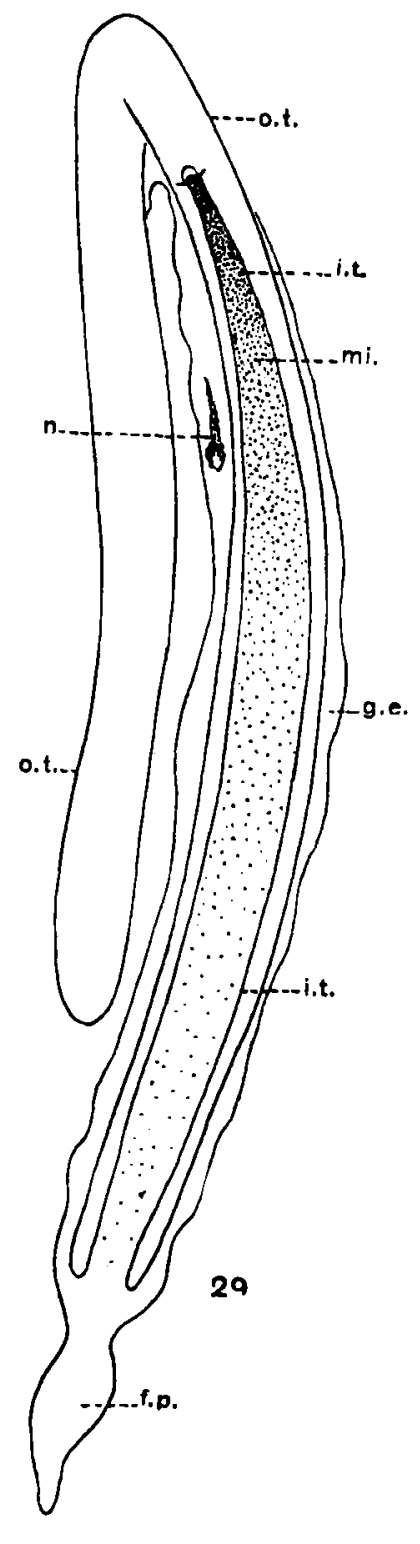

679 


\section{PLATE 7}

\section{EXPLANATION OF FIGURES}

28 Proximal end of young spermatozoon showing further growth of the inner tube. The cilia-like fibers at its apex have given place to a clear vesicle.

31 Spermatozoon from smear preparation, showing the transformation which occurs while it is within the spermatophore sac. The complete evagination of the inner tube from within the outer results in the formation of one continuous tube. The nucleus and the mitochondria now lie at opposite ends of this tube and the nucleus, together with much of the gelatinous envelop and the fingerform process is now within the tube. The flagellum $(f$.$) hangs down within the$ tube. The dotted lines represent the length of that portion of the spermatozoon which is omitted from the drawing. 

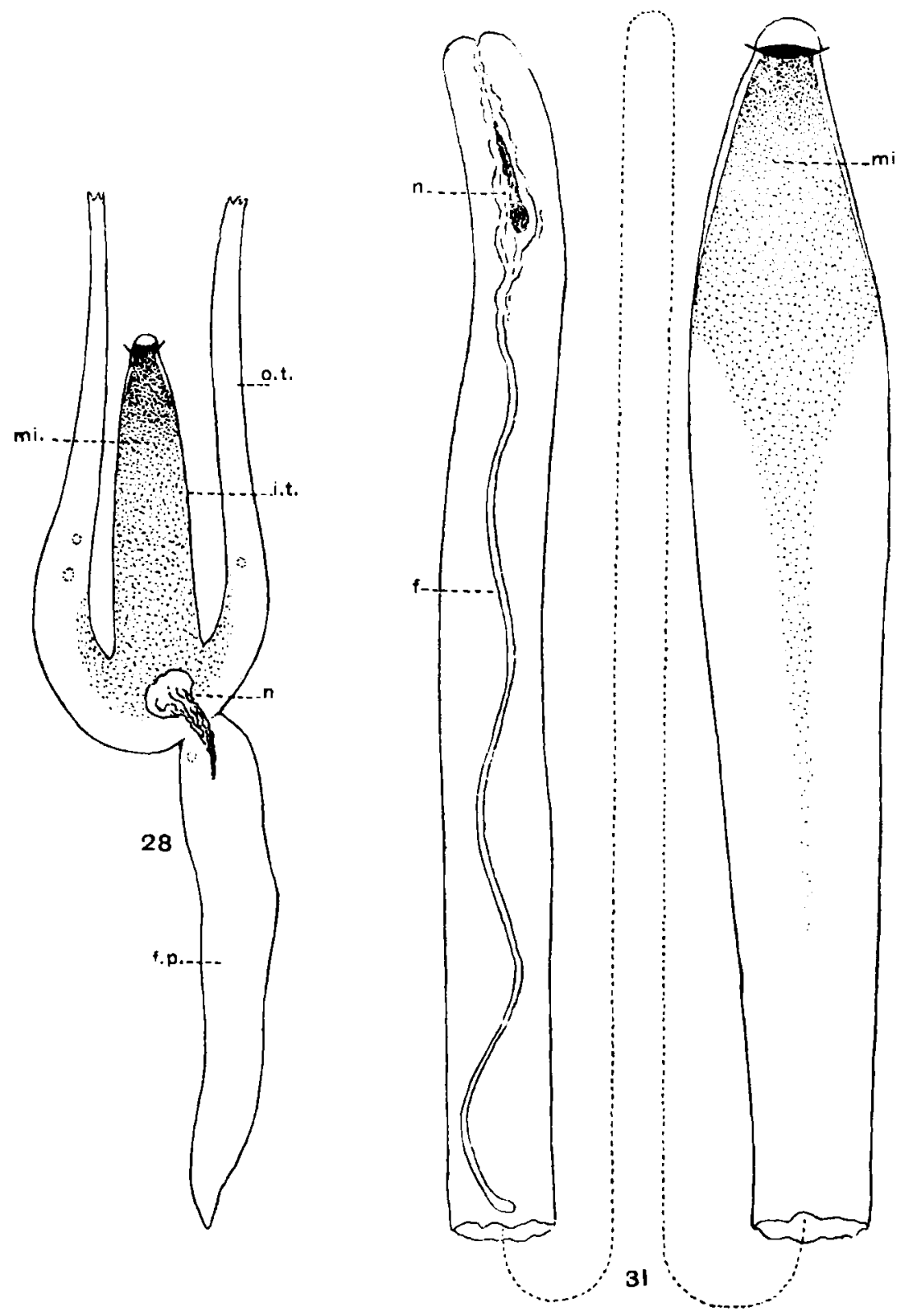


\section{PIAATE 8}

\section{EXPLANATION OF FIGURES}

32 Nuclear end of living spermatozoon in which the flagellum is beginning to protrude from the tube.

33 Nuclear end of living spermatozoon with flagellum fully extended.

34 Mitochondria-bearing end of a living spermatozoon in the same stage of development as that in figure 33 . The vesicle at the tip is surrounded by a circlet of short processes. The tube is ridged and somewhat flattened. 

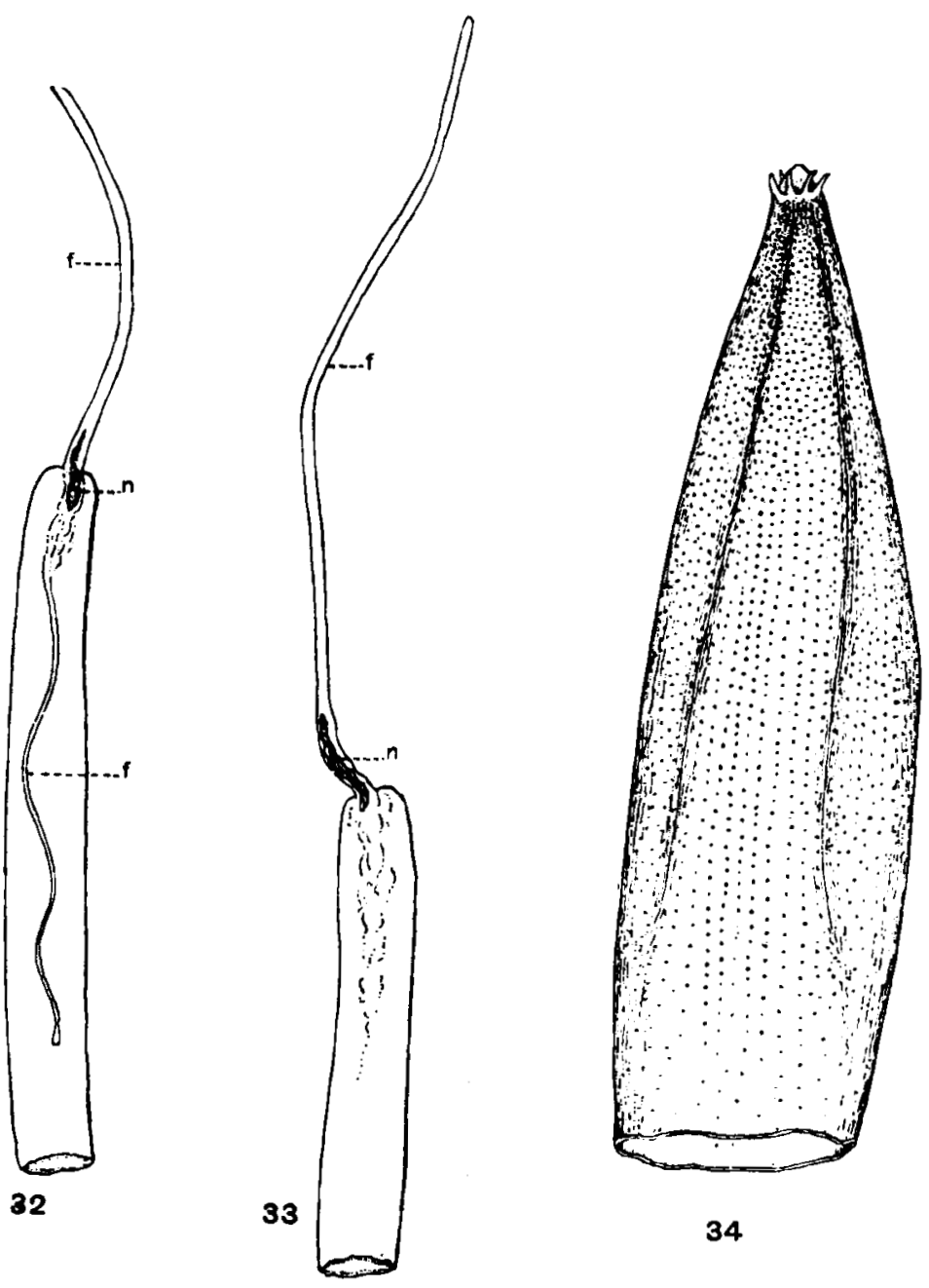